\section{Prevalence of Insomnia and Factors Associated with it Among the Elderly People of Sarangdanda VDC in Panchthar District}

\begin{abstract}
Raj Kumar Subedi
Abstract

Insomnia is one of the major and unsolved problems in older people. Most of the sleep studies report that the different forms of insomnia like Difficulty Initiating Sleep (DIS), Difficulty Maintaining Sleep (DMS) and Non-Restorative Sleep (NRS) are common among the elderly that are associated to many factors. The objective of the study was to measure the prevalence of insomnia and the factors associated to it among the elderly people.A cross-sectional study was conducted among 142 elderly people of and above 60 years of age in Sarangdanda VDC of Panchthar District of Eastern Nepal. The presence or absence of insomnia and the associated factors were assessed on them by the help of interview schedule. The results were analyzed using chisquare test in SPSS (version 11.5). DMS was the most common reported form of insomnia among the elderly followed by DIS and NRS. Association between insomnia and each of factors like use of tobacco before sleeping hours, eating too close to bedtime, use of tea/coffee before sleeping hours and use of alcohol before sleeping hours were statistically significant at 95\% level of confidence. Insomnia affects a large proportion of elderly and is triggered by many factors like use of tobacco before sleeping hours, use of tea/coffee before sleeping hours, eating too close to bedtime and use of alcohol before sleeping hours.
\end{abstract}

Keywords: Alcohol, tea/coffee, difficulty initiating sleep (DIS), difficulty maintaining sleep (DMS), non-restorative sleep (NRS), tobacco

\section{Introduction}

Ageing is a natural phenomenon and an inevitable process. It is closely related with the dynamic process of demographic and socio-economic transformation. There are various factors that make a person old. Decrease in physical strength, increase in mental tension, decrease in immunity power and getting sick to a large extent are the major features that make a person aged. Elderly people also experience many physical changes. With the increase in age, people lose their creativity level, problem solving ability and learning skills as well as short-term memory (Paudel, 2005).

As a person ages, sleep becomes more fragmented (Who Gets Insomnia, 2008). There are a number of common contributors to sleep disorders: stress, bladder or kidney disorders, odd work schedules, eating a heavy meal right before bedtime, incorrect diet for your particular body's needs, uncomfortable mattress, and caffeine, alcohol, or nicotine use late in the day (New Solutions for old Sleep Problems, 2003). Poor sleep has been shown to be associated with lower working capacity, dissatisfaction with work and high levels of work stress, and self-reported sick leave (Sivertsen, 2006). Insomnia is a condition which affects millions of individuals, giving rise to emotional distress, daytime fatigue, and loss of productivity (Sateia, Doghramji, \& Hauri, 2000).

A study conducted in Iceland revealed that DMS is the commonest form of insomnia among the elderly that affects $37 \%$ of the males and $30 \%$ of the females. Daytime napping was reported by $50 \%$ of the men and $31 \%$ of the women $(\mathrm{P}<0.001)$ (Gislason, Reynisdottir, Kristbajarnarson, \& Benediktsdottir, 1993). Similarly in the USA, the frequencies of five common sleep complaints-trouble falling asleep, waking up, awaking too early, needing to 
nap and not feeling rested--were assessed in over 9,000 participants aged 65 years and older in the National Institute on Aging's multicentered study entitled "Established Populations for Epidemiologic Studies of the Elderly" (EPESE). Between 23\% and $34 \%$ had symptoms of insomnia and between $7 \%$ and $15 \%$ percent rarely or never felt rested after waking up in the morning (Foley, Monjan, Brown, Simonsick, Wallace, \& Blazer, 1995). Drug use, including caffeine, alcohol, nicotine, and prescribed medications, can also cause sleep disturbances. Patients commonly underestimate the stimulatory effects of even small amounts of caffeine early in the day. A trial period of complete abstinence from caffeine, cigarettes, and alcohol is recommended for any patient with insomnia (McCall, 2005).

There has been the decreasing order of the people who can take care of the elderly within the family in the rural areas making them vulnerable to many physical and mental health problems. The mental health problems among the elderly have led to many social and behavioral problems. Such mental health problems need to be diagnosed in time to prevent the social and behavioral health problems like suicide which is two times higher among the elderly with sleep disturbances than those without sleep disturbances (Ancoli \& Cooke, 2005). In many communities a number of factors are responsible for insomnia among the elderly. However, no researches have been documented yet in Nepal regarding this issue. Further Researches need to be done regarding the Elderly Issues in a social context so as to increase their quality of life.

\section{Methods and Materials}

A total of 142 Elderly people above 60 years of age representing all the wards were selected as the study participants out of total 542 elderly people in the Sarangdanda VDC of Panchthar District. The elderly people who were suffering from other diseases were not included in the study. Systematic sampling method was used for data collection purpose. The interview schedule was prepared and made standardized with some standard references like DSM-IV, ICD-10, and Pittsburgh Insomnia Rating Scale.

The questionnaire was pretested among the elderly of a VDC in Gorkha District. The questions were asked in Nepali language and the simple words were used while asking questions that helped correct understanding of the questions by the respondents to get correct information from them. The data was collected by direct interview method. The researcher, along with two additional Human Resources collected the data. The data was edited manually after each day data. Then after, the coding of data was done prior to the entry in SPSS program. The data cleaning was done accordingly. The cleaned data was hence analyzed and interpreted.

Informed verbal consent was taken from the elderly before asking him/her the questions. Similarly, the respondents were requested to answer all the questions. The respondent was allowed to quit if they didn't further want to respond. The respondents were assured of their privacy and confidentiality.

\section{Findings and Discussion}

Among 142 respondents, majority of them i.e. 31.7\% were of 60 65 years of age, followed by the consecutive age groups. Mean age of the respondents was 69.3 years and the age group ranged from 60 years to 88 years. The standard deviation of the age was 6.285 years.

Among 142 respondents, 54.2 percent of them were male. About 69 percent of the total respondents belonged to the joint family. The average family size was found to be 5.64 . The family size ranged from 2 to 11 with a standard deviation of 2.59. Most of the respondents were married (81.7\%) followed by widow/widower (11.3\%) and separated (7\%). Among 142 respondents, more than half of them were Rai and Limbu followed by the people of other ethnicity like Chhetri, Newar and Dalits. The combined percentage 
of Rai and Limbu was 57\%. Of the total respondents, majority of them belonged to Kirant religion $60.6 \%$ followed by Hindu and Buddhists. It was because majority of the respondents were Rai and Limbu who entirely belonged to the Kirant Religion. Similarly, majority of them $73.9 \%$ had agriculture as their occupation followed by business (12.7\%) and service (4.2\%). The SocioDemographic characteristics of the respondents are given in Table 1.

Table 1: Socio-Demographic Characteristics of the Respondents $(\mathrm{n}=142)$

\begin{tabular}{|l|l|l|l|}
\hline Characteristics & Category & Frequency & Percent \\
\hline Age Group & $60-65$ & 45 & 31.7 \\
\hline & $65-70$ & 42 & 29.6 \\
\hline & $70-75$ & 28 & 19.7 \\
\hline & $75+$ & 27 & 19.0 \\
\hline & Male & 77 & 54.2 \\
\hline & Female & 65 & 45.8 \\
\hline & & & \\
Family Type & Nuclear & 43 & 30.3 \\
\hline & Joint & 99 & 69.7 \\
\hline & Chhetri & 32 & 22.5 \\
\hline & Newar & 4 & 2.8 \\
\hline & Rai & 25 & 17.6 \\
\hline & Limbu & 56 & 39.4 \\
\hline & Dalit & 12 & 8.5 \\
\hline & Others & 13 & 9.2 \\
\hline & Hindu & 49 & 34.5 \\
\hline Religion & Kirat & 86 & 60.6 \\
\hline & Buddhist & 7 & 4.9 \\
\hline & & & \\
\hline & Married & 116 & 81.7 \\
\hline & & &
\end{tabular}

\section{4 | Raj Kumar Subedi}

\begin{tabular}{|l|l|l|l|}
\hline & Widow/Widower & 16 & 11.3 \\
\hline & Separated & 10 & 7.0 \\
\hline & & & \\
Occupation & Agriculture & 105 & 73.9 \\
\hline & Service & 6 & 4.2 \\
\hline & Business & 18 & 12.7 \\
\hline & Others & 13 & 9.2 \\
\hline Total & & & \\
\hline
\end{tabular}

\subsection{Forms of Insomnia Among the Elderly}

The respondents were asked questions to assess the different forms of insomnia in them i.e. Difficulty Initiating Sleep (DIS), Difficulty Maintaining Sleep (DMS) and Non-Restorative Sleep (NRS). Of the total respondents, 49.3 percent of them said that they had the problem of Difficulty Initiating Sleep. The mean time taken to initiate sleep on most nights was 49.72 minutes. Time taken to fall asleep on most nights ranged from 15 minutes to 210 minutes with standard deviation of 33.47 minutes.

Difficulty maintaining sleep was the most common form of insomnia among the elderly i.e. 61.3 percent. After waking up on most nights, majority of the respondents said that it took more than 30 minutes for them to fall back to sleep i.e. 57.8\%. The mean time taken to fall sleep after waking up in the night was 46.16 minutes and it ranged from 15 minutes to 120 minutes with a standard deviation of 21.641 minutes. Majority of the elderly didn’t have the problem of early morning awakening only 28.9 percent of the elderly woke up early in the morning before they wanted to.

Similarly, among 142 elderly respondents, 45.1 percent had the problem of waking up not fully rested. The different forms of Insomnia that were present among the elderly are given in table 2. 
Table 2: Forms of Insomnia among the Elderly $(n=142)$

\begin{tabular}{|c|l|c|c|c|}
\hline $\begin{array}{c}\text { S. } \\
\text { N. }\end{array}$ & \multicolumn{1}{|c|}{ Type of Insomnia } & Presence & $\begin{array}{c}\text { Number of } \\
\text { Respondents }\end{array}$ & Percent \\
\hline & & & & \\
\hline 1 & $\begin{array}{l}\text { Difficulty Initiating Sleep } \\
\text { (DIS) }\end{array}$ & Yes & 70 & 49.3 \\
\hline & \multicolumn{1}{|c|}{ No } & 72 & 50.7 \\
\hline 2 & $\begin{array}{l}\text { Difficulty Maintaining } \\
\text { Sleep (DMS) }\end{array}$ & Yes & 87 & 61.3 \\
\hline & \multicolumn{1}{|c|}{ No } & 55 & 31.7 \\
\hline 2.1 & $\begin{array}{l}\text { Time taken to fall sleep } \\
\text { after }\end{array}$ & & & \\
\hline & waking up on most nights & Yes & 60 & 42.3 \\
\hline & $0-30$ minutes & Yes & 67 & 47.2 \\
\hline & $30-60$ minutes & Yes & 15 & 10.6 \\
\hline & $60-120$ minutes & Yes & 41 & 28.9 \\
\hline 2.2 & Early Morning Awakening & No & 101 & 71.1 \\
\hline & & Yes & 64 & 45.1 \\
\hline 3 & $\begin{array}{l}\text { Non-Restorative } \\
\text { (NRS) }\end{array}$ & No & 78 & 54.9 \\
\hline & & & 142 & 100 \\
\hline & & & \\
\hline & Total & & & \\
\hline
\end{tabular}

\subsection{Habits before Sleeping Hours}

Of the total respondents, majority of the respondents i.e. 56.3\% responded that they had the habit of taking tea/coffee before sleeping hours. Most of them used to take tea before sleeping hours. Similarly, majority of the respondents said that they had the habit of eating too close to bedtime i.e. 66.9 percent. Similarly, 59.2 percent respondents had the habit of tobacco use before sleeping hours. Similarly, 51.4 percent respondents said that they had the habit of alcohol intake before sleeping hours. Most of them used to take liquor such jaand or raksi that made at home. The different types of behaviors regarding eating too close to bedtime;

\section{6 | Raj Kumar Subedi}

and use of alcohol, tea/coffee, and tobacco before sleeping hours are given in table 3.

Table 3. Habits among Elderly before Sleeping ( $\mathrm{N}=142)$

\begin{tabular}{|l|l|l|l|}
\hline Type of Habits & Yes/No & Frequency & Percent \\
\hline Use of tea/coffee & & & \\
\hline & Yes & 80 & 56.3 \\
\hline Eating too close to bedtime & No & 62 & 43.7 \\
\hline & Yes & 95 & 66.9 \\
\hline $\begin{array}{l}\text { Use of tobacco before sleeping } \\
\text { hours }\end{array}$ & No & 47 & 33.1 \\
\hline & Yes & 84 & 59.2 \\
\hline $\begin{array}{l}\text { Use of alcohol before sleeping } \\
\text { hours }\end{array}$ & No & 58 & 40.8 \\
\hline & Yes & 73 & 51.4 \\
\hline & No & 69 & 48.6 \\
\hline Total & & & \\
\hline & & 142 & 100 \\
\hline
\end{tabular}

3.3 Insomnia and Different Habits among Elderly before Sleeping

Majority of the respondents who had the habit of tea/coffee intake before sleeping hours had insomnia. The Pearson-Chi square value was 36.89 with P- value less than 0.05 . Hence, the insomnia was significantly higher among the elderly who had the habit of tea/coffee intake before sleeping hours than those who didn't.

Majority of the respondents who had the habit of eating too close to bedtime had insomnia. The Pearson- chi square value obtained was 26.052 with P-value less than 0.05. Hence insomnia was significantly higher among the elderly who had the habit of eating too close to bedtime than those who didn't have. 
Majority of the respondents who smoked before sleeping hours had insomnia. The Pearson-Chi square value was 76.99 for the use of tobacco before sleeping hours and insomnia with P-value less than 0.05 . Hence the prevalence of insomnia was significantly higher among the elderly who had the habit of tobacco intake before sleeping hours than those who didn't.

Similarly, majority of the respondents who had the habit of smoking before sleeping hours had insomnia. The Pearson-Chi square value for the association between smoking before sleeping hours and insomnia was 34 with $P$ value less than 0.01 . Hence the prevalence of insomnia was significantly higher among the elderly who had the habit of alcohol intake before sleeping hours than those who hadn't. The association between insomnia and different types of behaviors before sleeping hours is given in table 4 .

Table 4: Insomnia and Different Habits among Elderly before Sleeping $(\mathrm{n}=142)$

\begin{tabular}{|l|l|l|l|l|}
\hline Type of Habits before Sleeping & \multicolumn{2}{|c|}{$\begin{array}{c}\text { Insomnia } \\
\text { (at least 1 type) }\end{array}$} & $\begin{array}{c}\text { Chi- } \\
\text { square } \\
\text { value }\end{array}$ & $\begin{array}{c}\text { P- } \\
\text { value }\end{array}$ \\
\hline Tea/coffee intake before sleeping & Yes & No & & \\
\hline & & & & \\
\hline Yes & 68 & 12 & 36.89 & $<0.01$ \\
\hline No & 22 & 40 & & \\
\hline Eating too close to bedtime & & & & \\
\hline Yes & 74 & 21 & 26.05 & $<0.01$ \\
\hline No & 16 & 31 & & \\
\hline Use of tobacco before sleeping & & & & \\
\hline Yes & 78 & 6 & 76.99 & $<0.01$ \\
\hline No & 12 & 46 & & \\
\hline Use of alcohol before sleeping & & & & \\
\hline Yes & 63 & 10 & 34.01 & $<0.01$ \\
\hline No & 27 & 42 & & \\
\hline
\end{tabular}

The study was aimed to identify the different forms of insomnia among the elderly and to examine the association between insomnia and each of the factors like use of caffeine before sleeping hours, eating too close to bedtime, use of tobacco before sleeping hours and use of alcohol before sleeping hours.

Sateia MJ, Doghramji K, Hauri P, et al. (2000) found that insomnia, or inability to sleep, is the most commonly reported sleep problem in the world (Sateia, Doghramji, \& Hauri, 2000). Epidemiological trends towards a 'graying' population make the issue of insomnia in the elderly an increasingly important research and clinical topic (Moller, Barbara, Kayumov, \& Shapiro, 2004). Insomnia is an experience of inadequate or poor quality sleep characterized by one or more of the following: (1) difficulty falling asleep (sleep-onset insomnia), (2) difficulty maintaining sleep, (3) waking up too early in the morning (early morning awaking) and (4) non-refreshing sleep (non-restorative sleep) that affects mainly the elderly (Tanaka \& Shirakawa, 2004). A study in Greece revealed that insomnia affects the elderly predominantly (Patelaros \& Argyriadou, 2004). Similarly this study also revealed all these forms of insomnia among the elderly i.e. DIS, DMS and NRS.

A study in Japan revealed that about 1 in 10 elderly people are reported to have difficulty falling asleep, 1 in 5 to have night awakenings and 1 in 8 to awake too early in the morning (Tanaka \& Shirakawa, 2004). Similarly this study revealed that about $49.3 \%$ of the elderly are suffering from difficulty initiating sleep, about $57.8 \%$ had the problem of falling back to sleep after waking up in the night and about $28.9 \%$ of the elderly had the problem of early morning awakening.

A study conducted among the elderly in USA revealed that between $23 \%$ and $34 \%$ had symptoms of insomnia and between $7 \%$ and $15 \%$ percent rarely or never felt rested after waking up in the morning (Foley, Monjan, Brown, Simonsick, Wallace, \& 
Blazer, 1995). Similarly this study revealed that about $63 \%$ of the elderly had one or more forms of insomnia. Similarly about $45 \%$ of the elderly had the problem of waking up having not fully rested.

A study conducted in Iceland revealed that DMS is the commonest form of insomnia among the elderly that affects about $34 \%$ of the population (Gislason, Reynisdottir, Kristbajarnarson, \& Benediktsdottir, 1993). Similarly, this study showed that about $61 \%$ of the elderly in Sarangdanda VDC of Panchthar district were suffering from DMS which was also the most common reported form of insomnia among the elderly.

A study in USA revealed that caffeine intake before sleeping hours, smoking before sleeping hours and use of alcohol before sleeping hours were associated with insomnia among the elderly (Foley, Monjan, Brown, Simonsick, Wallace, \& Blazer, 1995). Similarly this study also showed that association between insomnia and each of the factors like use of caffeine before sleeping hours, use of tobacco before sleeping hours and use of alcohol before sleeping hours was statistically significant with P-value 0.001 for each association. A study in Japan revealed that eating too close to bedtime was associated with insomnia (Tanaka \& Shirakawa, 2004). This study also revealed the association between eating too close to bedtime and insomnia that was statistically significant with $P$ value less than 0.001 .

The incidence of insomnia in this study is high as compared to the similar kind of studies from other countries. It might be because of the difference in the socio-demographic characteristics, economic status and lifestyle. The socio-behavioral characteristics of people living in this VDC are not same as those of the elderly of developed countries like USA and Japan. Further research needs to be done to regarding this issue.

Thus, in this study, the association between the hypothesized factors i.e. insomnia and use of tea/coffee before bedtime; insomnia and use of tobacco before bedtime; insomnia and eating too close to bedtime; and; insomnia and use of alcohol before bedtime are found to be statistically significant.

\section{Conclusion}

Insomnia is any one of the conditions characterized by inability to fall asleep, inability to maintain sleep or to wake up having not fully rested. The different forms of insomnia were assessed among the elderly people of Sarangdanda VDC of Panchthar District. Similarly, the different factors associated to insomnia like use of caffeine before sleeping hours, eating too close to bedtime, use of tobacco before sleeping hours and use of alcohol before sleeping hours also assessed among them.

Majority of the respondents had the habit of taking tea before bedtime. More than half had the habit of talking alcohol before sleeping hours. Majority of the respondents ate too close to bedtime. Majority of the respondents had the habit of taking tobacco before bedtime. Difficulty maintaining Sleep (DMS) was the most common form of insomnia among the elderly followed by NRS (Non-Restorative Sleep) \& DIS (Difficulty Initiating Sleep) respectively.

Insomnia was higher among the elderly who used caffeine before sleeping hours than those who didn't as well as among those who used caffeine before sleeping hours than those who didn't. Insomnia was found to be higher among the elderly who used alcohol before sleeping hours then those who didn’t as well as among the elderly who had the habit of using tobacco before sleeping hours than those who didn't have. The associations were also found to be statistically significant.

The study could only incorporate the behavioral factors due to limitation of time, budget and manpower. So, more researches need 
to be conducted that include more factors like disease condition, depression, anxiety, psychological abuse and neglect etc.

\section{References}

New Solutions for old Sleep Problems. (2003, February). Retrieved April 10, 2008, from Health alternatives 2000.com: http://www.healthalternatives2000.com/sleeplessnesssolution.html

Who Gets Insomnia. (2008). Retrieved April 8, 2008, from EhealthMD:http://www.ehealthmd.com/library/insomnia/I NS_who.html

Ancoli, S., \& Cooke, J. R. (2005, July). Prevalence and Comorbidity of Insomnia and Effect on Functioning in Elderly Populations. Journal of American Geriatric Society, 53(s7), s264-s271.

Foley, D., Monjan, A., Brown, S., Simonsick, E., Wallace, R., \& Blazer, D. (1995, July). Sleep complaints among elderly persons: an epidemiologic study of three communities. Sleep, 18(6), 425-432.

Gislason, T., Reynisdottir, H., Kristbajarnarson, H., \& Benediktsdottir, B. (1993, July). Sleep habits and sleep disturbances among the elderly-an epidemiological survey. Journal of Internal Medicine, 234(1), 31-39.

McCall, W. V. (2005, July). Diagnosis and Management of Insomnia in Older People. Journal of the American Geriatrics Society, s272-s277.

Moller, H. J., Barbara, J., Kayumov, L., \& Shapiro, C. M. (2004, February). Psychiatric Aspects of Late-life insomnia. Sleep Medicine Reviews, 8(1), 31-45.

Patelaros, E., \& Argyriadou, S. (2004, June). Investigation of insomnia among the elderly in primary care settings in Greece: the efficient collaboration of GPs and psychiatrists. Primary care Mental Health, 2(2), 115-121.

Paudel, N. (2005, July 8). Problems of elderly Population.
Retrieved April 8, 2008, from Nepal News: http://www.nepalnews.com.np/contents/englishweekly/spo tlight/2005/jul/jul08/national5.php

Sateia, M., Doghramji, K., \& Hauri, P. (2000). Evaluation of Chronic Insomnia. An American Academy of Sleep Medicine, 23(2), 243-308.

Sivertsen, B. (2006). Insomnia in older adults, Consequences, assessment and treatment. Dissertation for the Degree of Philosophiae doctor (PhD). University of Bergen, Norway.

Tanaka, H., \& Shirakawa, S. (2004, May). Sleep health, lifestyle and mental health in the Japanese elderly: ensuring sleep to promote a healthy brain and mind. Journal of Psychosomatic Research, 56(5), 465-477. 